\title{
Differential Effects of the CRF-RI Antagonist GSK876008 on Fear-Potentiated, Light- and CRF-Enhanced Startle Suggest Preferential Involvement in Sustained vs Phasic Threat Responses
}

\author{
David Walker*,', Yong Yang ', Emiliangelo Ratti ${ }^{2}$, Mauro Corsi ${ }^{2}$, David Trist ${ }^{2}$ and Michael Davis ${ }^{1,3}$ \\ 'Department of Psychiatry and Behavioral Sciences, School of Medicine, Emory University, Atlanta, GA, USA; ${ }^{2}$ GlaxoSmithKline Medicines \\ Research Centre, Verona, Italy; ${ }^{3}$ The Center for Behavior Neuroscience, Emory University, Atlanta, GA, USA
}

\begin{abstract}
The amplitude of the acoustic startle response is increased when elicited in the presence of brief cues that predict shock (fearpotentiated startle) and also when elicited during sustained exposure to bright light (light-enhanced startle). Although both effects are thought to reflect fear or anxiety, their neuroanatomical substrates differ. Although fear-potentiated startle is disrupted by reversible inactivation of the central nucleus of the amygdala (CeA) but not the closely related bed nucleus of the stria terminalis (BNST), lightenhanced startle is disrupted by BNST inactivation but not by CeA inactivation. Intraventricular infusions of corticotropin-releasing factor (CRF) also increase startle (CRF-enhanced startle) and this effect is mediated by CRF receptors within the BNST, with no involvement of the CeA. Together, these observations suggest that CeA- and BNST-dependent fear and anxiety may be differentially sensitive to CRF receptor blockade. We tested this by orally administering the novel, potent, and selective CRF-RI antagonist GSK876008 to rats before CRF-enhanced, light-enhanced, or fear-potentiated startle testing. GSK876008 disrupted CRF-enhanced startle with a linear dose-response curve, and light-enhanced startle with a U-shaped dose-response curve, but did not disrupt fear-potentiated startle to a visual stimulus at any dose tested, and even augmented the response in some animals. GSK876008 also disrupted shock-related 'baseline' startle increases, which may have reflected context conditioning (shown elsewhere to also be BNST-dependent). Overall, these results suggest that short-duration CeA-dependent threat responses can be pharmacologically dissociated from longer duration BNSTdependent responses in terms of their sensitivity to CRFI receptor antagonists.
\end{abstract}

Neuropsychopharmacology (2009) 34, I533- I542; doi:I0. I038/npp.2008.2 I0; published online 10 December 2008

Keywords: fear; anxiety; startle; amygdala; bed nucleus of the stria terminalis; corticotropin-releasing factor

\section{INTRODUCTION}

Healthy fear and clinical anxiety share many of the same symptoms. As such, the neural substrates of experimentally induced fear have often been studied to better understand those of anxiety. We have done so using changes in the amplitude of the acoustic startle response as a behavioral measure. Indeed, the amplitude of the startle reflex can be modified by a variety of stimuli including conditioned fear cues (eg, brief stimuli previously paired with shockBrown et al, 1951) and also, in rats, by sustained exposure to bright light - a putative anxiety response to increased vulnerability (Walker and Davis, 1997a).

\footnotetext{
*Correspondence: Dr D Walker, Department of Psychiatry, Emory University School of Medicine, 954 Gatewood Road, Yerkes Neuroscience Bldg-Rm 5214, Atlanta, GA 30329, USA, Tel: + I 404 727-3587, Fax: + I 404727 8070, E-mail: dlwalke@emory.edu Received 16 July 2008; revised 3 October 2008; accepted 16 October 2008
}

Although fear-potentiated and light-enhanced startle are both disrupted by benzodiazepines and other anxiolytic compounds (de Jongh et al, 2002; Walker and Davis, 1997a, 2002a), the neuroanatomical substrates of the two phenomena differ, with fear-potentiated startle requiring AMPA receptor activation in the central nucleus of the amygdala $(\mathrm{CeA})$ but not the closely related bed nucleus of the stria terminalis (BNST), and light-enhanced startle requiring just the opposite - ie, AMPA receptor activation in the BNST but not the CeA (Walker and Davis, 1997b). Based on these and other observations, we have suggested that the CeA and BNST may be key components of functionally distinct threat-response systems, with rapid-onset short-duration threat responses being mediated by rapid excitatory transmission in the CeA, and more slowly developing sustained responses being mediated by ionotropic and perhaps metabotropic receptor activity in the BNST (compare, Walker et al, 2003). We have also suggested that BNST-dependent effects such as light-enhanced startle, 
which are typically characterized by a relatively slow onset and offset (eg, compare Davis et al, 1989; with de Jongh et al, 2003) and which may occur in the absence of any extant threat at all, may be more closely related to anxiety than to stimulus-specific fear (compare, Walker and Davis, 2008). If so, then pharmacological treatments that selectively interfere with BNST function might be especially useful for the treatment of at least some types of anxiety symptoms, and perhaps disorders.

In this regard, corticotropin-releasing factor (CRF) antagonists are particularly interesting. CRF-R1 protein and mRNA are abundant in the BNST but sparse in the CeA (Potter et al, 1994; Van Pett et al, 2000; Wynn et al, 1984), and CRF infusions into the BNST (Lee and Davis, 1997), but not amygdala (Liang et al, 1992), increase startle amplitude. Moreover, the startle-enhancing effects of i.c.v. CRF infusions are blocked by excitotoxic BNST lesions and also by intra-BNST infusions of the CRF1/2 antagonist $\alpha$-helical $\mathrm{CRF}_{9-41}$, but are not blocked by neurotoxic CeA lesions (Lee and Davis, 1997).

Consistent with the view that BNST-dependent threat responses are especially sensitive to CRF receptor blockade (eg, relative to CeA-dependent responses), de Jongh et al (2003) found that i.c.v. $\alpha$-helical $\mathrm{CRF}_{9-41}$ infusions nonmonotonically disrupted light-enhanced startle but had no effect on fear-potentiated startle to a 3.7-s conditioned fear stimulus (CS) at the same or a fivefold higher dose. This may reflect a genuine difference in the involvement of CRF receptors in these two types of responses or, alternatively, preferential access of BNST neurons to i.c.v.-infused CRF, insofar as the BNST (eg, unlike the CeA) lies immediately adjacent to the lateral ventricle. In fact, Schulz et al (1996) reported that systemic administration of the selective CRF-R1 antagonist CP154,526 did disrupt fear-potentiated startle, Fendt et al (1997) reported that $\alpha$-helical $\mathrm{CRF}_{9-41}$ infusions into the caudal reticular formation also disrupted fearpotentiated startle, and Swerdlow et al (1989) reported that i.c.v. $\alpha$-helical $\mathrm{CRF}_{9-41}$ infusions did so as well (ie, seemingly in direct contrast to the results reported by de Jongh et al, 2003). Although these studies suggest that fear-potentiated startle can be disrupted by CRF receptor antagonists under some circumstances, they are not inconsistent with the view that longer duration BNST-dependent startle increases are more sensitive because in all but de Jongh et al (2003), the effect of the antagonist on BNST-dependent startle increases was not evaluated in parallel.

A primary goal of this study then was to directly compare the sensitivity of CeA-dependent fear-potentiated and BNST-dependent light-enhanced startle to systemic administration of the novel, potent, and selective nonpeptide CRF-R1 antagonist GSK876008 (Di Fabio et al, in press), after first evaluating in the same animals the effect of the same doses on an unambiguously CRF-mediated effect, CRF-enhanced startle.

\section{MATERIALS AND METHODS}

\section{Animals}

Adult (300-350 g at the time of arrival) Sprague-Dawley rats (Charles River, Raleigh, NC) were group-housed (4 per cage) and a maintained on a 12-h light/dark cycle with lights on at 0800 hours and free access to food and water. A total of 45 female and 49 male rats were used for the primary experiment (ie, in which each rat was tested first for CRF-enhanced startle, then for light-enhanced startle, and then for fear-potentiated startle). An additional 28 male and 28 female rats were used in a supplemental experiment in which rats were tested for fear-potentiated startle only. Both genders were used in these experiments because we wished to evaluate the reliability of our previous finding (Toufexis et al, 2005) that females show greater light-enhanced startle than males, and to see if similar differences would be observed with respect to CRF-enhanced startle, which is also BNST-dependent, but not fear-potentiated startle, which is not. All procedures were conducted in accordance with USDA, NIH, and Emory University guidelines for the care and use of laboratory animals.

\section{Apparatus}

Rats were trained and tested in four identical $8(\mathrm{l}) \times 15(\mathrm{w}) \times 15(\mathrm{~h})-\mathrm{cm}$ Plexiglas and wire mesh cages, each with four $6.0-\mathrm{mm}$ diameter stainless steel floorbars.

Startle responses were evoked by 50 -ms white-noise bursts generated by a Macintosh G3 computer sound file, amplified by a Radio Shack amplifier (100 W, Model MPA-200; Tandy, Fort Worth, TX), and delivered through Radio Shack Supertweeter speakers located $5 \mathrm{~cm}$ in front of each cage. Background noise ( $60 \mathrm{~dB}$ wideband) was provided by a General Radio (Concord, MA) Type 1390-B noise generator and delivered through the same speakers used for the startle stimulus. Startle response amplitudes were quantified using a PCB Piezotronics (Depew, NY) accelerometer (model U321AO2) affixed to the bottom of each cage. Displacement of the accelerometer by the rats' startle response produced a voltage output that was integrated by a PCB Piezotronics signal conditioner (Model 483B21) and digitized by a GW Instruments (Somerville, MA) Instrunet device (Model 100B). Startle amplitude was defined as the maximum peak-to-peak voltage of the Instrunet's output during the first $200 \mathrm{~ms}$ after each noise burst, and was quantified in arbitrary units from 0.000 to 1.998 (linear scale).

Illumination for light-enhanced startle testing (150lux), and for the CS during fear-potentiated startle testing (82 lux) was provided by Med Associates Inc. (Georgia, VT) PHM-258 fluorescent bulbs located $10 \mathrm{~cm}$ behind each cage. The footshocks used $(0.5 \mathrm{~s}, 0.4 \mathrm{~mA})$ for fear conditioning were delivered through the floorbars and were generated by LeHigh Valley (Beltsville, MD) shock generators (model SGS-004).

The presentation and sequencing of all stimuli was under the control of a Macintosh G3 computer using customdesigned software (The Experimenter; Glassbeads Inc., Newton, CT).

\section{Drugs and Drug Administration}

GSK876008 was synthesized by the Medicinal Chemistry Department of GlaxoSmithKline Medicines Research Centre (Verona, Italy), prepared as a suspension in $0.5 \%(\mathrm{w} / \mathrm{v})$ hydroxypropylmethylcellulose, and administered p.o. at a volume of $2 \mathrm{ml} / \mathrm{kg}$, and doses ranging from 0.1 to $60 \mathrm{mg} / \mathrm{kg}$. Previous findings indicate that GSK876008 shows a CNS 
bioavailability of $66 \%(58-73 \%$, CL95) and a half-life of $1.6 \mathrm{~h}$ (1.4-1.7 h CL95) following oral administration at $10 \mathrm{mg} / \mathrm{kg}$, with exposure increasing linearly up to doses of $300 \mathrm{mg} / \mathrm{kg}$ (Di Fabio et al, in press). In vitro, GSK876008 shows a functional potency $\left(\mathrm{pA}_{2}\right)$ of $7.14 \pm 0.12$ on recombinant human $\mathrm{CRF} 1$ receptors expressed in $\mathrm{CHO}$ cells, but is inactive on human CRF2 receptors or the CRF binding protein, or on 83 other G-protein coupled receptors, channels, enzymes and transporters up to a concentration of $10 \mu \mathrm{M}$ (Di Fabio et al, in press).

CRF (human/rat) was purchased from Peninsula Laboratory (San Carlos, CA), dissolved in ACSF, and infused into the lateral ventricle $(1 \mu \mathrm{g} / 5 \mu \mathrm{l}$ per $5 \mathrm{~min})$ through 28 -gauge injection cannulae (Model C313I; Plastics One, Roanoke, VA) using a pump-controlled Hamilton microsyringe. Injection cannulae were left in place for $60 \mathrm{~s}$ after the infusion was completed.

\section{General Design and Experimental Sequence}

Each rat in the primary study was tested sequentially (each test approximately 1 week apart) for CRF-enhanced, then light-enhanced, and then fear-potentiated startle after receiving one of several GSK876008 doses $(0,0.1,0.3,1,3$, 10,30 , or $60 \mathrm{mg} / \mathrm{kg}$; p.o.). Each individual rat received the same dose for each of the three tests. Doses were selected based on previous findings that GSK876008 disrupts separation-induced vocalizations in rat pups at 30 and $60 \mathrm{mg} / \mathrm{kg}$ (i.p.), CRF-induced forepaw treading in gerbils at 10 and $30 \mathrm{mg} / \mathrm{kg}$ (p.o.), and anxiety-related behavior in the marmoset human threat test at 3, 10, and $30 \mathrm{mg} / \mathrm{kg}$ (p.o.; Di Fabio et al, in press). An additional group of rats was tested for fear-potentiated startle without having first been tested for CRF- or light-enhanced startle.

\section{Surgery}

Rats were anesthetized with sodium pentobarbital $(50 \mathrm{mg} /$ $\mathrm{kg}$, i.p.), injected with an analgesic dose of buprenorphine $(0.01 \mathrm{mg} / \mathrm{kg}$, s.c.; repeated approximately $12 \mathrm{~h}$ postsurgery), and with atropine $(0.04 \mathrm{mg} / \mathrm{kg}$, s.c.) to prevent pulmonary congestion. Using standard stereotaxic procedures, 22-gauge guide cannulae (model C313G; Plastics One) were lowered into the lateral ventricle $(\mathrm{AP}=-0.4, \mathrm{DV}=-5.5$, $\mathrm{ML}=+1.2 \mathrm{~mm}$ from bregma; flat-skull position), and cemented in place using Cranioplastic Powder (Plastic One). Stainless steel wires, cut so as to protrude approximately $1 \mathrm{~mm}$ from the guide cannulae's tips, were inserted to maintain patency, and stainless steel lock nuts screwed onto the top to prevent rats from chewing the cannulae and dislodging the wire.

\section{CRF-Enhanced Startle}

After 7-10 days of the surgery, rats were acclimated to the experimental context and stimuli during an initial test consisting of 30 95-dB noise bursts (interstimulus interval $=30 \mathrm{~s}$ ). On the following day, rats received a preinfusion baseline startle test identical to that just described and, immediately thereafter, GSK876008 $(0.1,0.3,1,3,10,30$, or $60 \mathrm{mg} / \mathrm{kg}$ ) or vehicle. Two hours later, they received an intraventricular infusion of either CRF $(1 \mu \mathrm{g})$ or ACSF
( $5 \mu \mathrm{l} / 5 \mathrm{~min})$ followed $1 \mathrm{~h}$ later by a second startle test consisting of $12095-\mathrm{dB}$ noise bursts. One week later, this process was repeated except that rats that had initially received CRF now received ACSF and vice versa (for both tests, they received the same dose of GSK876008).

For each rat, ACSF and CRF proportion of preinfusion baseline scores (ie, postinfusion/preinfusion startle amplitude) were calculated. CRF-enhanced startle was expressed as a percent change score according to the formula: (CRF proportion of baseline score - ACSF proportion of baseline score)/ACSF proportion of baseline score) $\times 100$.

\section{Light-Enhanced Startle}

No less than 1 week after the final CRF-enhanced startle test, rats received another acclimation session and, on the following day, the first of two light-enhanced startle tests (1 week apart). Each of the two tests was composed of two consecutive phases during which rats received 30 startleeliciting noise bursts. For one of these tests, phase I noise bursts were presented in the dark and phase II noise bursts in the light. For the other test (counterbalanced), phases I and II noise bursts were both presented in the dark. Two hours before each test, rats were given the same dose of GSK876008 $(0,0.1,0.3,1,3,10,30$, or $60 \mathrm{mg} / \mathrm{kg})$ that they had previously received before CRF-enhanced startle testing.

For each rat, dark $\rightarrow$ dark and dark $\rightarrow$ light proportion of baseline scores were calculated (ie, phase II startle amplitude / phase I startle amplitude). Light-enhanced startle was expressed as a percent change score according to the formula: ( $($ dark $\rightarrow$ light proportion of baseline score - dark $\rightarrow$ dark proportion of baseline score)/dark $\rightarrow$ dark proportion of baseline score) $\times 100$.

\section{Fear-Potentiated Startle}

Approximately 1 week later, rats received on each of two consecutive days, 10 pairings of a 3.7-s light and coterminating footshock (intertrial interval $=3,4$, or $5 \mathrm{~min}$, randomly ordered). Twenty-four hours later, they received a brief fear-potentiated startle test consisting of 30 95-dB noise bursts with 5 of the final 10 (randomly ordered) occurring $3.2 \mathrm{~s}$ after CS onset. Data from this initial test were used to verify that the mean fear-potentiated startle level in the different treatment groups was similar before drug administration and, in the supplemental experiment described below, to assign rats to different treatment groups to ensure that it was. Twenty-four hours later, they again received GSK876008 $(0,0.1,0.3,1,3,10,30$, or $60 \mathrm{mg} / \mathrm{kg})$ and two hours later a second fear-potentiated startle test consisting of $6095-\mathrm{dB}$ noise bursts, of which 30 were presented in the presence and 30 in the absence of the CS.

As described in the results section, GSK876008 had no obvious effect on fear-potentiated startle to the 3.7-s CS in this, the primary experiment. To ensure that this was not due to previous drug exposure (ie, during CRF- and lightenhanced startle testing), the effect of 0,3 , and $10 \mathrm{mg} / \mathrm{kg}$ GSK876008 was re-evaluated in an additional group of 12 male and 12 female rats that had not previously received drug (or been tested for CRF- or light-enhanced startle). We also considered the possibility that drug effects on 
fear-potentiated startle might be more apparent in rats trained with weaker conditioning procedures. Therefore, another group (16 males and 16 females) was trained using a single day of conditioning consisting of 10 pairings of very weak $0.25-\mathrm{mA}$ footshocks and light (ie, vs 2 days of 10 pairings with $0.4 \mathrm{~mA}$ footshocks).

Fear-potentiated startle was expressed as percent change scores according to the formula: ((startle amplitude on CS trials - startle amplitude on noise burst alone trials)/startle amplitude on noise burst alone trials) $\times 100$.

\section{Statistical Analyses}

Percent potentiation scores, calculated as described above, were screened for outliers using the interquartile range test, which rejects scores laying more than 3 times the interquartile range (ie, Q3-Q1) above the third quartile or below the first. The remaining scores were analyzed with ANOVA, using dose and gender as between-subjects factors, and the shape of the dose-response curves evaluated with linear and quadratic contrast tests. The scores for each dose were obtained from a minimum of two replications and were normalized to the mean potentiation score of vehicletreated rats, which were included in each run, according to the formula: (individual percent potentiation score - mean vehicle percent potentiation score). For illustrative purposes, the mean level of potentiation in the control group was added to these difference scores.

To assess drug effects on baseline startle, each rat's mean startle amplitude under the influence of the antagonist was calculated from the two preinfusion and two dark phase I tests of CRF- and light-enhanced startle testing, respectively (ie, after GSK876008 administration but before the startle potentiating treatment of either CRF or light). These startle scores were then assessed with ANOVA using dose and gender as factors, and baseline startle amplitude without the antagonist (from the initial drug-free acclimation session) as a covariate. 'Baseline' startle from the fearpotentiated startle test (ie, noise alone test trials) was not included in this analysis because fear that may have incidentally conditioned to the shock context and influenced startle amplitude would have confounded such an analysis.

In fact, although this study was not designed with the specific intent of evaluating GSK876008 effects on context conditioning (a phenomenon that we have typically found to be quite modest), such an analysis was possible. To do so, the mean startle amplitude of each rat to the $95-\mathrm{dB}$ noise alone trials of the fear-potentiated startle test (ie, those that were presented in the absence of the explicit visual CS) was divided by that rat's mean startle amplitude to the $95-\mathrm{dB}$ noise bursts during phase I of the preceding light-enhanced startle test (ie, the most recent test trials which occurred in the dark before fear conditioning). For both conditions then, rats were tested in the dark after having received the same dose of GSK876008. The essential difference was that one set of data was collected before, and another set of data was collected after rats had received footshocks in the test context. The resulting percent change scores were analyzed as described previously for fear-potentiated startle to the phasic CS.
All analyses were conducted using SPSS software (v13.0.0; Chicago, IL). The criterion for significance was set at $p<0.05$ (two-tailed).

\section{RESULTS}

\section{Baseline Startle Amplitude}

ANOVA on baseline startle amplitude following GSK876008 administration (Table 1) indicated a small but significant effect of gender, $F(1,77)=13.94$, with the mean startle amplitude of females being approximately $23 \%$ less than males (perhaps owing to their slightly lower weight), and also of baseline startle amplitude before GSK876008 administration as a covariate, $\mathrm{F}(1,77)=48.39$, but not of dose $(p=0.189)$. That GSK876008 did not significantly affect baseline startle amplitude is consistent with our subjective observations of the animals' behavior that druginjected rats did not exhibit overt motoric effects such as hyperactivity or ataxia that would have affected startle amplitude or its potentiation by CRF, light, or fear.

\section{CRF-Enhanced Startle}

Of the 94 rats that were tested for CRF-enhanced startle, the data from 5 were excluded due to problems with the infusion (eg, clogged cannulae), and the data from 4 others were excluded based on outlier criterion. Although these atypical responders - with percent potentiation scores of $599 \%(0 \mathrm{mg} / \mathrm{kg}), 964 \%(0.3 \mathrm{mg} / \mathrm{kg}), 491 \%(3 \mathrm{mg} / \mathrm{kg})$, and $624 \%(60 \mathrm{mg} / \mathrm{kg})$ - are potentially quite interesting on an individual basis, inclusion of their scores would grossly distort the group means and variability measures, and violate assumptions of normality required for analyses of the more representative animals presented below.

CRF-enhanced startle for the included rats is shown in Figure 1. ANOVA indicated a significant effect of GSK876008 dose, $F(7,69)=3.36$, but not of gender, $\mathrm{F}(1,69)=2.28, p=0.136$, with a significant fit of the doseresponse curve to a linear trend, $t(77)=3.94$.

\section{Light-Enhanced Startle}

Data were collected from 89 rats. Four rats that had been tested for CRF-enhanced startle were euthanized before light-enhanced startle testing due to lost headcaps, and the data from one rat were lost due to a technical problem. There were no outliers. The effect of GSK876008 on lightenhanced startle is shown in Figure 2. Although there was not a significant dose or gender effect overall, contrast tests indicated that the dose-response function was significantly fit to a quadratic trend, $t(81)=2.58$, thereby replicating the pattern previously reported by de Jongh et al (2003) who used i.c.v. infusions of $\alpha$-helical $\mathrm{CRF}_{9-41}$.

\section{Fear-Potentiated Startle}

For the primary experiment, data were collected from 90 rats (as previously indicated, 4 of the initial 94 rats were euthanized due to lost headcaps). There were no outliers. ANOVA on fear-potentiated startle (ie, from test trials without the 3.7-s CS to those with the CS; Figure 3) revealed 
Table I Raw Startle Values (group means) from Each of the Three Paradigms in the Primary Experiment (Open Cells)

\begin{tabular}{|c|c|c|c|c|c|c|c|c|c|c|c|c|c|c|c|}
\hline \multirow[b]{3}{*}{$\begin{array}{l}\text { Dose } \\
(\mathrm{mg} / \mathrm{kg})\end{array}$} & \multicolumn{6}{|c|}{ CRF-enhanced startle tests } & \multicolumn{6}{|c|}{ Light-enhanced startle tests } & \multicolumn{3}{|c|}{ Fear-potentiated startle test } \\
\hline & \multicolumn{3}{|c|}{ CSF control infusion } & \multicolumn{3}{|c|}{ CRF infusion } & \multicolumn{3}{|c|}{ Dark- $>$ dark control session } & \multicolumn{3}{|c|}{ Dark-> light session } & \multirow[b]{2}{*}{$\begin{array}{l}\text { Noise } \\
\text { alone }\end{array}$} & \multirow[b]{2}{*}{$\begin{array}{c}\text { Fear } \\
\text { CS+ } \\
\text { noise }\end{array}$} & \multirow[b]{2}{*}{$\begin{array}{c}w / C S \text { as } \\
\text { a \% of } \\
\text { noise alone }\end{array}$} \\
\hline & $\begin{array}{c}\text { Pre- } \\
\text { infusion }\end{array}$ & $\begin{array}{c}\text { Post- } \\
\text { infusion }\end{array}$ & $\begin{array}{c}\text { Post CSF as } \\
\% \text { of pre } \\
\text { CSF }\end{array}$ & $\begin{array}{c}\text { Pre- } \\
\text { infusion }\end{array}$ & $\begin{array}{c}\text { Post- } \\
\text { infusion }\end{array}$ & $\begin{array}{c}\text { Post CRF as } \\
\% \text { of Pre } \\
\text { CRF }\end{array}$ & $\begin{array}{c}\text { Dark } \\
\text { phase I }\end{array}$ & $\begin{array}{c}\text { Dark } \\
\text { phase } \\
\text { II }\end{array}$ & $\begin{array}{l}\text { Phase II } \\
\text { as \% of } \\
\text { phase I }\end{array}$ & $\begin{array}{l}\text { Dark } \\
\text { phase I }\end{array}$ & $\begin{array}{l}\text { Light } \\
\text { phase II }\end{array}$ & $\begin{array}{l}\text { Phase II } \\
\text { as \% of } \\
\text { phase I }\end{array}$ & & & \\
\hline 0 & 0.78 & 0.6 & 78 & 0.82 & 1.05 & 137 & 0.67 & 0.59 & 91 & 0.68 & 0.77 & 118 & 0.92 & 1.54 & 176 \\
\hline 0.1 & 0.65 & 0.44 & 68 & 0.73 & 0.9 & 139 & 0.53 & 0.59 & 109 & 0.7 & 0.82 & 124 & 1.06 & 1.82 & 173 \\
\hline 0.3 & 0.85 & 0.61 & 74 & 0.78 & 1.22 & 174 & 0.7 & 0.79 & 124 & 0.61 & 0.77 & 136 & I & 1.79 & 196 \\
\hline । & 1.18 & 1.23 & 104 & 1.29 & 2.38 & 187 & 0.93 & 0.93 & 92 & 1.08 & 1.13 & 101 & 1.18 & 2.05 & 164 \\
\hline 3 & 1.14 & 0.95 & 81 & 1.37 & 0.96 & 79 & 0.88 & 0.71 & 80 & 0.99 & 0.87 & 90 & 1.09 & 1.61 & 143 \\
\hline 10 & 1.16 & 0.82 & 71 & 1.15 & 0.98 & 88 & 0.71 & 0.76 & 130 & 0.74 & 0.72 & 104 & 1.12 & 1.67 & 156 \\
\hline 30 & 1.06 & 0.71 & 65 & 1.32 & 1.14 & 72 & 0.92 & 0.75 & 83 & 1.09 & 0.96 & 86 & 1.02 & 1.82 & 178 \\
\hline 60 & 1.15 & 0.61 & 56 & 1.35 & 0.91 & 69 & 0.59 & 0.49 & 81 & 0.58 & 0.63 & 111 & 0.69 & 1.03 & 156 \\
\hline
\end{tabular}

Shaded cells indicate mean percent-of-baseline measures (eg, (postinfusion / preinfusion) $\times 100$, in the case of CRF-enhanced startle). These values are based on the mean of the individual animal's percent-of-baseline scores and are, therefore, close but not exactly equivalent to the percent of baseline score which would be calculated from the group mean startle values shown in the unshaded cells.

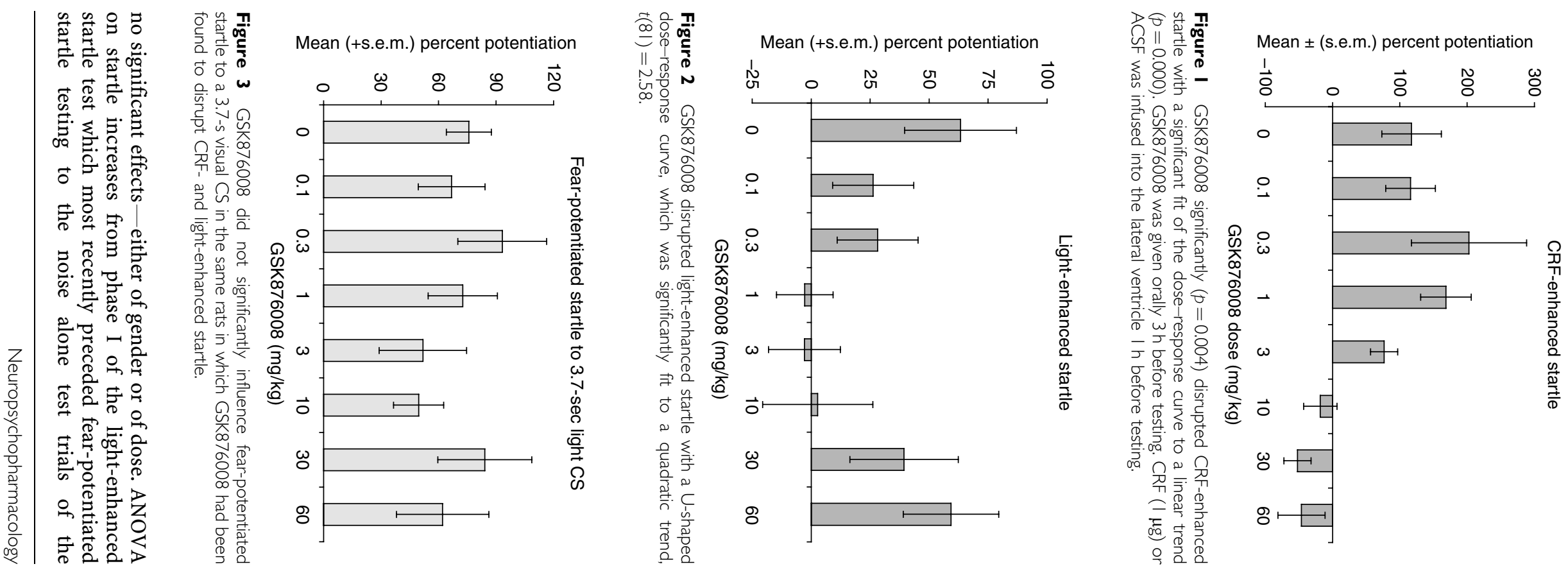




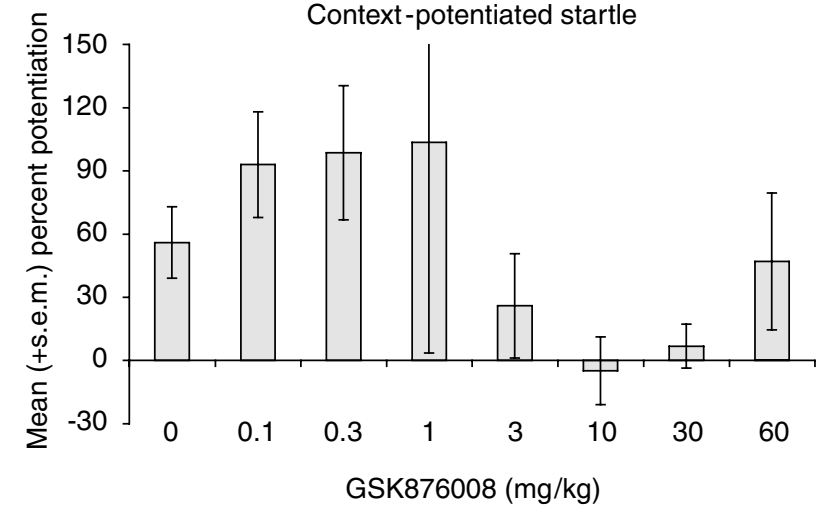

Figure 4 The percent change in startle amplitude from phase I of the most recent light-enhanced startle test (ie, startle to $95-\mathrm{dB}$ noise probes presented in the dark after administration of the CRF-RI antagonist, but before context-shock pairings) to startle amplitude during the noise alone trials of the fear-potentiated startle test (ie, startle to $95-\mathrm{dB}$ noise probes, in the dark, after administration of the CRF-RI antagonist, $48 \mathrm{~h}$ after contextshock pairings) is shown. GSK876008 dose-dependently disrupted the pre to post-conditioning startle increases.

fear-potentiated startle test itself (ie, possible contextpotentiated startle; Figure 4) also found no effect of dose or gender, but did indicate a significant fit of the doseresponse curve to a linear trend, $t(23.9)=2.87, p=0.009$ without assuming equal variances and $t(79)=1.95$, $p=0.055$ assuming equal variances. For this analysis, the data from a single outlier (285\% pre- to postshock startle increase) were excluded from the $10 \mathrm{mg} / \mathrm{kg}$ group. The quadratic trend was not significant, but it is perhaps noteworthy in view of the U-shaped dose-response function for light-enhanced startle that pre- to postshock startle increases in the $60 \mathrm{mg} / \mathrm{kg}$ group were higher than in the next three lower dose groups but not markedly lower than those in the vehicle group. In fact, there was some evidence for a bimodal distribution at $60 \mathrm{mg} / \mathrm{kg}$ with three high scores of 172,172 , and $181 \%$, and four low scores of $9,23,38$, and $81 \%$.

\section{Supplemental Analyses of CRF-Enhanced, Light- Enhanced, and Fear-Potentiated Startle Scores in Groups With Equated Baseline Startle Levels}

Although GSK876008 did not significantly influence baseline startle amplitude, there were nominal group differences due to random variation. To ensure that these differences did not somehow contribute to the apparent drug effects on CRF- and light-enhanced startle, and the noneffect on fearpotentiated startle, the analyses presented above were repeated after having equated the different groups for baseline startle amplitude by eliminating potentiation scores from rats with the lowest or highest baseline startle scores. To do this, the potentiation score of the rat with the lowest baseline startle amplitude was dropped from the group with the lowest mean baseline level, and the potentiation score of the rat with the highest baseline startle amplitude was dropped from the group with the highest mean baseline level. This procedure was repeated (separately for each paradigm) until the mean baseline level

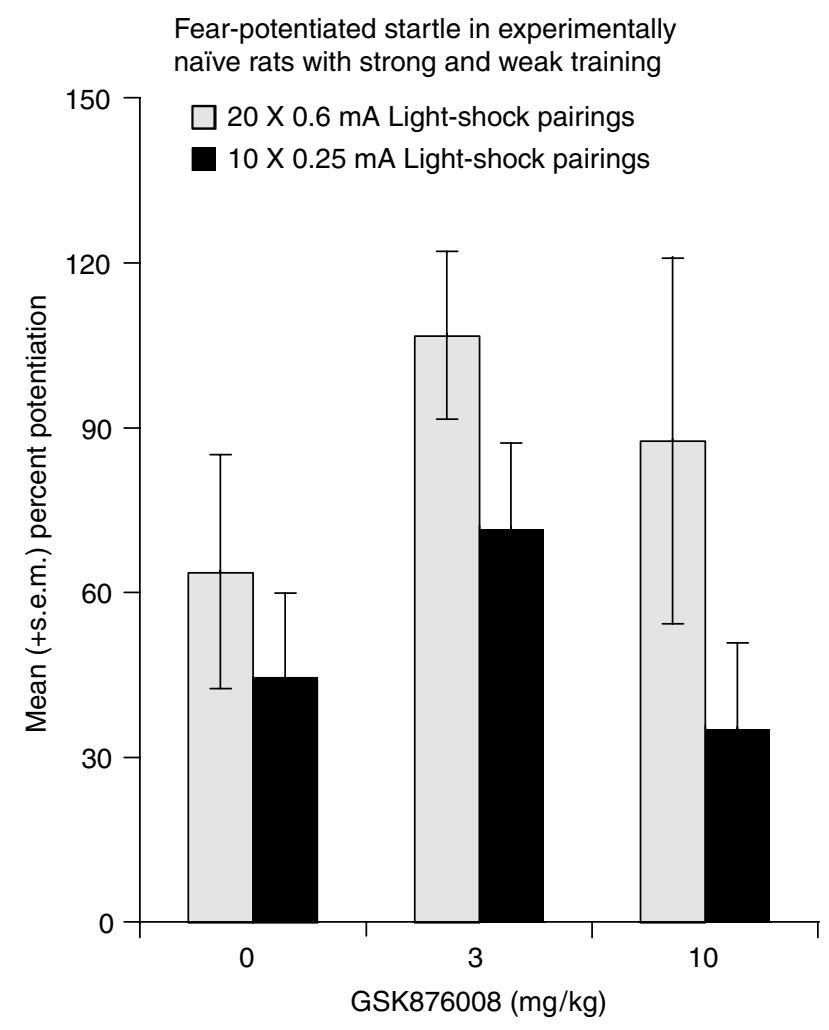

Figure 5 In this experiment, the effect of GSK876008 was tested in experimentally naive rats that had received either standard or weak fear conditioning. As before, the CRF-RI antagonist did not disrupt fearpotentiated startle but, in this experiment, actually augmented potentiation to the $3.7-\mathrm{s}$ visual $\mathrm{CS}$ at the $3 \mathrm{mg} / \mathrm{kg}$ dose (quadratic trend, $p<0.05$ ).

of the highest group was no more than $20 \%$ greater than that of the lowest group (the criteria was set in advance). This resulted in the elimination of 10 data points from the CRF-enhanced startle analysis (low group $=0.53$, high group $=0.64), 7$ from the light-enhanced startle analysis (low group $=0.63$, high group $=0.76$ ), and 5 from the fearpotentiated startle analysis (low group $=0.92$, high group $=1.09$ ) of the primary study. The results of these analyses were not substantively different from the same analyses performed on the full dataset. That is, ANOVA indicated a significant effect of dose, $F(7,73)=2.51$, for CRF-enhanced startle with a significant linear trend $t(66)=3.53$; no main effect of dose for light-enhanced startle but a significant fit of the dose-response curve to a quadratic trend, $t(74)=2.14$, and no significant effect of any sort for fear-potentiated startle to the 3.7-s visual CS.

\section{Analysis of Fear-Potentiated Startle in Drug-Naive Rats with Strong vs Weak Fear Conditioning}

The effect of 3 and $10 \mathrm{mg} / \mathrm{kg}$ GSK876008 (ie, doses that maximally disrupted light-enhanced startle and completely blocked CRF-enhanced startle) was re-evaluated in a new group of rats using standard as well as weak conditioning procedures. GSK876008 again failed to disrupt fear-potentiated startle, but appeared instead to enhance fearpotentiated startle at the $3 \mathrm{mg} / \mathrm{kg}$ dose (Figure 5). Statistically, ANOVA indicated significant main effects of protocol 
(ie, weak $v s$ strong training), $\mathrm{F}(1,43)=9.10$, and also of dose, $F(2,43)=3.57$, with the dose-response curve significantly fit to a quadratic trend, $t(52)=2.24$.

\section{DISCUSSION}

Previous findings indicate that CRF-enhanced startle is mediated by the activation of CRF receptors within the BNST (Lee and Davis, 1997). Other findings indicate that light-enhanced but not fear-potentiated startle is also dependent on the BNST, whereas fear-potentiated but not light-enhanced startle is dependent on AMPA receptormediated transmission in the CeA (eg, Walker and Davis, 1997b). These dissociations suggest the existence of two functionally distinct fear/anxiety systems, and raise the possibility that BNST-dependent anxiety may be especially sensitive to CRF-R1 blockade. That possibility was evaluated here using the novel, potent, and selective CRF-R1 antagonist GSK876008.

When delivered $2 \mathrm{~h}$ before CRF infusions and $3 \mathrm{~h}$ before testing, GSK876008 dose-dependently disrupted CRF-enhanced startle, completely blocking the effect at GSK876008 doses of $10 \mathrm{mg} / \mathrm{kg}$ and higher. These results are consistent with those of Risbrough et al $(2003,2004)$ who found that systemic injections of the selective CRF-R1 antagonists NBI30775 or R121919 significantly attenuated CRF-enhanced startle in mice, and with those of Schulz et al (1996) who found that systemic injection of the CRF-R1 antagonist CP154,526 blocked CRF-enhanced startle in rats. At least in mice, CRF2 receptors appear to play a relatively minor role - perhaps augmenting the effect of CRF1 receptors, but having little if any effect on startle by themselves (Risbrough et al, 2003, 2004).

Light-enhanced startle was also disrupted by GSK876008 and appeared to be more sensitive to lower GSK876008 doses than CRF-enhanced startle. This difference in sensitivity most likely reflects the greater difficulty in overcoming behaviors produced by pharmacological CRF administration compared to physiological CRF release. Our results indicated a U-shaped dose-response function, mirroring very closely the results of de Jongh et al (2003) who found that i.c.v. infusions of 5 but not $25 \mu \mathrm{g} \alpha$-helical $\mathrm{CRF}_{9-41}$ also disrupted light-enhanced startle. In principle, nonmonotonic dose-response curves obtained with $\alpha$ helical $\mathrm{CRF}_{9-41}$ could reflect antagonist binding to the CRF binding protein (CRF-BP), which might then lead to an increase in free CRF (Behan et al, 1996). This would not explain our results however because GSK876008 is a nonpeptide antagonist that does not bind to CRF-BP (tested at concentrations up to $10 \mu \mathrm{M}$; D Trist, unpublished data). Nor does it account for the fact that monotonic doseresponse curves have been obtained with this compound in several other paradigms including CRF-induced gerbil forepaw treading (up to $30 \mathrm{mg} / \mathrm{kg}$, p.o.), the human-threat test in marmosets (up to $30 \mathrm{mg} / \mathrm{kg}$, p.o.), and the separation-induced vocalization tests in rat pups (up to $60 \mathrm{mg} / \mathrm{kg}$, i.p.; Di Fabio et al, in press). An alternative account for the dose-response function obtained with light-enhanced startle is presented at the end of this section.

Although Toufexis et al (2005) and de Jongh et al (2005) have both found light-enhanced startle to be greater in female than in male rats, gender did not significantly influence light-enhanced startle in this study. This suggests that the effect of gender on light-enhanced startle is unreliable or, alternatively, not robust against seemingly minor procedural variations. For example, in our experience, female rats are noticeably more reactive to handling, and more active in general, compared to male rats. Such reactivity may promote light-enhanced startle, but wane with repeated testing as the animals habituate to handling and the general experimental procedures. Indeed, there was some evidence for this in the baseline startle data, which decreased more rapidly in females (from 1.03 to 0.8 to 0.6 ) than in males (from 1.09 to 1.11 to 0.83 ) from the initial acclimation session to the CRF- and then light-enhanced startle test sessions. Perhaps then, these inconsistently observed gender differences with respect to light-enhanced startle are more apparent in experimentally naive rats.

In contrast to the disruptive effects on CRF- and lightenhanced startle, but consistent with results from several other studies that used other CRF receptor antagonists and different routes of administration (de Jongh et al, 2005; Lee and Davis, 1997; and see unpublished observations referred to in Risbrough and Geyer, 2005), we found no evidence that GSK876008 disrupted fear-potentiated startle to the 3.7s visual CS. In fact, GSK876008 dose-dependently augmented fear-potentiated startle to the visual CS in the supplemental experiment. This is consistent with other observations from our laboratory that GSK876008 also augments, albeit inconsistently, fear-potentiated startle to short-duration white noise and clicker CSs (DL Walker, LA Miles, and M Davis, in preparation).

Although GSK876008 did not affect baseline startle, there were nominal, preexisting between-group differences. We are confident, however, that these did not contribute to between-group differences in potentiation scores. First, the statistical analyses presented earlier are based on percent change scores. We have previously shown that when fear levels remain constant, percent change scores also remain constant, even across baseline differences (eg, due to individual variability, startle probe intensity, or drug manipulations) far greater than those noted here (Walker and Davis, 2002b). Second, even though the general pattern of between-group differences in baseline startle was constant across the three paradigms, the general pattern of potentiation scores was not-with the dose of GSK876008 related monotonically to CRF-enhanced startle, nonmonotonically to light-enhanced startle, and not at all to fear-potentiated startle in the primary experiment. Perhaps most compelling, when the same analyses were repeated after equating the different groups for baseline startle amplitude (ie, by culling out the lowest responders in lowbaseline groups and the highest responders in high baseline groups), the outcomes of the statistical tests were not substantively altered.

In our view, one of the most important aspects of this study is the side-by-side comparison of GSK876008 effects on light-enhanced $v s$ fear-potentiated startle. As in de Jongh et al (2003), our results clearly indicate that the two types of responses - although superficially identical (ie, both being an increase in startle to a visual stimulus) - can be pharmacologically dissociated. In the case of our results, this dissociation cannot readily be attributed to differential 
access to relevant receptor populations because the antagonist was administered orally. At a minimum then, the different effects of GSK876008 on fear-potentiated $v s$ light-enhanced startle indicate a differential sensitivity to CRF-R1 blockade. The fact that fear-potentiated startle, with either strong or weak training, was not disrupted but actually enhanced in some animals suggests to us a more fundamental dissociation.

From a neuroanatomical perspective, we believe this fundamental dissociation may be related to the dependency of light-enhanced startle on the BNST and of fear-potentiated startle on the CeA. Functionally, we have suggested that these two brain areas may be preferentially involved in long- $v s$ short-duration threat responses, respectively (compare, Walker et al, 2003) - a view consistent with recent findings from Waddell et al (2006) who showed that BNST lesions block conditioned suppression to 10- but not 1-min clicker CSs, and from Sullivan et al (2004) who showed that BNST lesions disrupt freezing and corticosterone responses to a 5 min context CS but not to a 20-s tone CS (and see also Resstel et al, 2008, for BNST inactivation effects on cardiovascular responses to a context CS).

We did not design our study with the specific intent of assessing context conditioning, but the design of experiment 1 did allow for such an analysis. The results of that analysis are consistent with the view that GSK876008 also disrupted context-potentiated startle. Effects of CRF receptor blockade on context-potentiated startle have not, to our knowledge, been previously reported, although effects on context CS-induced freezing have (eg, Deak et al, 1999; Hikichi et al, 2000; Kalin and Takahashi, 1990). We emphasize the point that in the same animals in which GSK876008 appeared to disrupt context-potentiated startle, it clearly did not block fear-potentiated startle to the 3.7-s CS. As context discrimination controls were not included in our study, we cannot exclude the possibility that the pre- to postshock startle increases were nonassociative (eg, shockinduced sensitization). However, as long-lasting shockinduced sensitization of the startle response also appears to be a BNST-dependent effect (Gewirtz et al, 1998; DL Walker and $M$ Davis, in preparation), that interpretation would also be consistent with the view that BNST-dependent startle increases, and sustained threat responses more generally, are especially sensitive to CRF receptor blockade. In fact, there appears to be a growing list of behavioral effects ranging from social defeat (eg, Jasnow et al, 1999, 2004) to learned helplessness (Hammack et al, 2004; Mansbach et al, 1997) to stress-induced reinstatement of drug-seeking behavior (Erb and Stewart, 1999), for which susceptibility to BNST manipulations appears to be predictive of susceptibility to CRF receptor blockade. In addition, Sahuque et al (2006) and Lee et al (2008) have now reported anxiogenic effects of direct infusions into the BNST of CRF receptor agonists. If then, clinical anxiety or a subset of anxiety disorders were shown to involve either normal or dysregulated BNST activity, then CRF-R1 antagonists might be especially effective in alleviating their symptoms.

The complementary roles of the CeA and BNST, and the dependence of responses mediated by the latter on CRF, offer one possible explanation for the nonmonotonic disruptive effect of CRF receptor blockade on light- a

Initial response

Threat stimulus

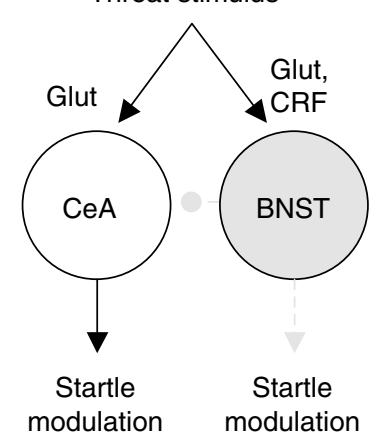

Figure 6 Schematic drawing illustrating hypothetical involvement of the $\mathrm{CeA}$ and BNST in short- and long-duration startle increases, and of the functional relationship of these two areas with one another. In this model, the CeA (specifically, the medial subdivision) responds immediately to neural activity which signals threat, whereas the BNST responds more slowly, perhaps requiring the sustained activation of CRF receptors. Once online however, threat-elicited responses such as increased startle are mediated by the BNST, whose neurons then inhibit the CeA neurons, which mediate the initial response. If the BNST were taken offline (eg, with sufficient CRF receptor blockade), then according to this model the $\mathrm{CeA}$ should once again be free to respond. Open circles and solid lines indicate active neurons and connections; gray circles and dashed lines indicate inactive or suppressed neurons and connections.

enhanced startle seen here and elsewhere (de Jongh et al, 2003) and perhaps also for the nonmonotonic facilitatory effect observed less consistently with respect to fearpotentiated startle (Walker and Davis, 2008; Figure 4; and present results). As depicted in Figure 6, we believe that threat-encoding neurons project to both the CeA and the BNST, activating the former (CeA) rapidly and the latter (BNST) more slowly. We also hypothesize that the BNST sends an inhibitory signal to the phasic fear system. In fact, the BNST does send a substantial projection to the specific part of the CeA (ie, the medial CeA - Dong and Swanson, 2004; Dong et al, 2001; Sun and Cassell, 1993) thought to mediate phasic startle increases (eg, Campeau and Davis, 1995; Rosen et al, 1991). Although the influence of this projection on medial CeA neurons is uncertain, anatomical (Huber et al, 2005) and electrophysiological (Collins and Pare, 1999; Huber et al, 2005) findings suggest that lateral CeA neurons, which are more closely affiliated with the BNST and a major source of its CRF input (eg, Sakanaka et al, 1986), do inhibit medial CeA neurons.

In response to a sustained threat stimulus then, the initial effect on startle would be mediated by direct and indirect projections from the medial $\mathrm{CeA}$ to brainstem areas that mediate the basic startle reflex. During a sustained threat signal, as CRF is released into the BNST and its neurons gradually come on line, it too would influence startle amplitude by way of its own projections to these same brainstem areas. This increase in the BNST's activity would be accompanied by a concurrent decrease in the medial CeA's role, due to active inhibition by the BNST. If however, the BNST were to be inactivated (eg, by high doses of a CRF receptor antagonist), then the inhibitory signal to the CeA would be lost, allowing $\mathrm{CeA}$ neurons to once again participate in the behavioral response. This then could 
generate a U-shaped dose-response function such as that observed with light-enhanced startle, assuming that the behavioral effect of the inhibitory output to CeA neurons was more resistant to disruption than the behavioral effect of the CeA's modulatory outputs to the brainstem. That is, at low doses the CRF-R1 antagonist would block enough receptors in the BNST to decrease light-enhanced startle but not enough to disinhibit the CeA. At higher doses, the CRF-R1 antagonist would prevent both effects, allowing $\mathrm{CeA}$ neurons to once again mediate startle increases, this time to sustained light. Importantly, disinhibition would not result in a U-shaped dose-response function for CRFenhanced startle, or other behaviors that are independent of the $\mathrm{CeA}$, because in these cases, with no signal impinging on the $\mathrm{CeA}$, there would be nothing to disinhibit. The model also predicts that in cases where there was already some degree of tonic BNST activity (either evoked or spontaneous), inactivation might actually augment responses to phasic threat signals. Indeed, this very effect has been reported by Meloni et al (2006) who found that direct infusions of the GABA-A agonist muscimol into the BNST markedly potentiated fear-potentiated startle to a 3.7-s visual CS. All of this is very speculative of course, and presented primarily as one possible explanation for the nonmonotonic dose-response curve reported here and in other studies, and as a conceptual framework for the design of future experiments.

Overall, these findings add to a growing body of evidence arguing for a fundamental distinction between two types of threat responses - functionally characterized, perhaps, by response duration, mediated by unique anatomical substrates, and distinguished by unique pharmacological vulnerabilities.

\section{ACKNOWLEDGEMENTS}

This research was supported by National Institute of Mental Health grants MH069056, MH47840, MH57250 and MH59906, and the Science and Technology Center (The Center for Behavioral Neuroscience of the National Science Foundation under Agreement No. IBN-9876754) and the Yerkes Base Grant.

\section{DISCLOSURE/CONFLICT OF INTEREST}

Dr Corsi, Dr Ratti, and Dr Trist receive compensation as full time employees of GlaxoSmithKline (GSK), a manufacturer of ethical medicines for diseases of the central nervous system. Dr Davis is a Co-PI on a collaborative grant (NIMH 1 U19 MH06905602) from Emory University, the National Institute of Mental Health and GSK. NIMH funded the work carried out in this article. GSK did not directly support any of the research on this grant but did supply the GSK008 used in these studies. In the past, Dr Davis had one contract with AstraZeneca to test some of their compounds, received an unrestricted gift from them to support his laboratory, and gave two talks there for which he received honoraria as well as one in Washington DC for which he received an honorarium. None of these pertained to this article. Also unrelated to this article, Dr Davis has applied for a patent for the use of $\mathrm{D}$-cycloserine as an adjunct to psychotherapy and is a partner in a company called Therapade and is entitled to milestone payments and royalties should that technology be commercialized. He is a paid member of the SAB of a company called Therapy.

Note added in proof: In an article to be published in this journal, and currently available online (November 19, 2008; advance online publication), Risbrough and colleagues show in CRF-R1 and CRF-R2 knockout mice, that neither receptor type is necessary for fear-potentiated startle to phasic threat cues, but that both contribute to context conditioning and/or expression - a pattern of results highly consistent with that reported here.

\section{REFERENCES}

Behan DP, Khongsaly O, Liu XJ, Ling N, Goland R, Nasman B et al. (1996). Measurement of corticotropin-releasing factor (CRF), CRF-binding protein (CRF-BP), and CRF/CRF-BP complex in human plasma by two-site enzyme-linked immunoabsorbant assay. J Clin Endocrinol Metab 81: 2579-2586.

Brown JS, Kalish HI, Farber IE (1951). Conditional fear as revealed by magnitude of startle response to an auditory stimulus. $J$ Exp Psychol 41: 317-328.

Campeau S, Davis M (1995). Involvement of the central nucleus and basolateral complex of the amygdala in fear conditioning measured with fear-potentiated startle in rats trained concurrently with auditory and visual conditioned stimuli. J Neurosci 15: 2301-2311.

Collins DR, Pare D (1999). Reciprocal changes in the firing probability of lateral and central medial amygdala neurons. J Neurosci 19: 836-844.

Davis M, Schlesinger LS, Sorenson CA (1989). Temporal specificity of fear-conditioning: effects of different conditioned stimulus-unconditioned stimulus intervals on the fearpotentiated startle effect. J Exp Psychol Anim Behav Process 15: 295-310.

de Jongh R, Geyer MA, Olivier B, Groenink L (2005). The effects of sex and neonatal maternal separation on fear-potentiated and light-enhanced startle. Behav Brain Res 161: 190-196.

de Jongh R, Groenink L, van der Gugten J, Olivier B (2002). The light-enhanced startle paradigm as a putative animal model for anxiety: effects of chlordiazepoxide, flesinoxan and fluvoxamine. Psychopharmacology 159: 176-180.

de Jongh R, Groenink L, van der Gugten J, Olivier B (2003). Lightenhanced and fear-potentiated startle: temporal characteristics and effects of alpha-helical corticotropin-releasing hormone. Biol Psychiatry 54: 1041-1048.

Deak T, Nguyen KT, Ehrlich AL, Watkins LR, Spencer RL, Maier SF et al. (1999). The impact of the nonpeptide corticotropinreleasing hormone antagonist antalarmin on behavioral and endocrine responses to stress. Endocrinology 140: 79-86.

Di Fabio R, St-Denis Y, Sabbatini FM, Andreotti D, Arban R, Bernasconi $G$ et al. (in press). Synthesis and pharmacological characterization of novel drug-like corticotropin-releasing factor 1 antagonists. $J$ Med Chem.

Dong H-W, Swanson LW (2004). Organization of axonal projections from the anterolateral area of the bed nucleus of the stria terminalis. J Comp Neurol 468: 277-298.

Dong HW, Petrovich GD, Watts AG, Swanson LW (2001). Basic organization of projections from the oval and fusiform nuclei of the bed nuclei of the stria terminalis in adult rat brain. J Comp Neurol 436: 430-455.

Erb S, Stewart J (1999). A role for the bed nucleus of the stria terminalis, but not the amygdala, in the effects of corticotropinreleasing factor on stress- induced reinstatement of cocaine seeking. J Neurosci 19: RC35. 
Fendt M, Koch M, Schnitzler H-U (1997). Corticotropin-releasing factor in the caudal pontine reticular nucleus mediates the expression of fear-potentiated startle in the rat. Eur J Neurosci 9: 299-305.

Gewirtz JC, McNish KA, Davis M (1998). Lesions of the bed nucleus of the stria terminalis block sensitization of the acoustic startle reflex produced by repeated stress, but not fearpotentiated startle. Prog NeuroPsychopharmacol Biol Psychiatry 22: 625-648.

Hammack SE, Richey KJ, Watkins LR, Maier SF (2004). Chemical lesion of the bed nucleus of the stria terminalis blocks the behavioral consequences of uncontrollable stress. Behav Neurosc 118: 443-448.

Hikichi T, Akiyoshi J, Yamamoto Y, Tsutsumi T, Isogawa K, Nagayama H (2000). Suppression of conditioned fear by administration of CRF receptor antagonist CP-154,526. Pharmacopsychiatry 33: 189-193.

Huber D, Veinante P, Stoop R (2005). Vasopressin and oxytocin excite distinct neuronal populations in the central amygdala. Science 308: 245-248.

Jasnow AM, Banks MC, Owens EC, Huhman KL (1999). Differential effects of two corticotropin-releasing factor antagonists on conditioned defeat in male Syrian hamsters (Mesocricetus auratus). Brain Res 846: 122-128.

Jasnow AM, Davis M, Huhman KL (2004). Involvement of central amygdalar and bed nucleus of the stria terminalis corticotropinreleasing factor in behavioral responses to social defeat. Behav Neurosci 118: 1052-1061.

Kalin NH, Takahashi LK (1990). Fear-motivated behavior induced by prior shock experience is mediated by corticotropin-releasing hormone systems. Brain Res 509: 80-84.

Lee Y, Davis M (1997). Role of the hippocampus, bed nucleus of the stria terminalis and amygdala in the excitatory effect of corticotropin releasing hormone on the acoustic startle reflex. J Neurosci 17: 6434-6446.

Lee Y, Fitz S, Johnson PL, Shekhar A (2008). Repeated stimulation of CRF receptors in the BNST of rats selectively induces social but not panic-like anxiety. Neuropsychopharmacology 33: 2586-2594.

Liang KC, Melia KR, Miserendino MJD, Falls WA, Campeau S, Davis M (1992). Corticotropin-releasing factor: long-lasting facilitation of the acoustic startle reflex. J Neurosci 12: 2303-2312.

Mansbach RS, Brooks EN, Chen YL (1997). Antidepressant-like effects of CP-154,526, a selective CRF1 receptor antagonist. Eur J Pharmacol 323: 21-26.

Meloni EG, Jackson A, Gerety LP, Cohen BM, Carlezon Jr WA (2006). Role of the bed nucleus of the stria terminalis (BST) in the expression of conditioned fear. Ann NY Acad Sci 1071: 538-541.

Potter E, Sutton S, Donaldson C, Chen R, Perrin M, Lewis K et al. (1994). Distribution of corticotropin-releasing factor receptor mRNA expression in the rat brain and pituitary. Proc Natl Acad Sci USA 91: 8777-8781.

Resstel LB, Alves FH, Reis DG, Crestani CC, Correa FM, Guimaraes FS (2008). Anxiolytic-like effects induced by acute reversible inactivation of the bed nucleus of stria terminalis. Neuroscience 154: $869-876$.

Risbrough VB, Geyer MA (2005). Anxiogenic treatments do not increase fear-potentiated startle in mice. Biol Psychiatry 57: 33-43.

Risbrough VB, Hauger RL, Pelleymounter MA, Geyer MA (2003). Role of corticotropin releasing factor (CRF) receptors 1 and 2 in CRF-potentiated acoustic startle in mice. Psychopharmacology (Berl) 170: 178-187.

Risbrough VB, Hauger RL, Roberts AL, Vale WW, Geyer MA (2004). Corticotropin-releasing factor receptors CRF1 and CRF2 exert both additive and opposing influences on defensive startle behavior. J Neurosci 24: 6545-6552.

Rosen JB, Hitchcock JM, Sananes CB, Miserendino MJD, Davis M (1991). A direct projection from the central nucleus of the amygdala to the acoustic startle pathway: anterograde and retrograde tracing studies. Behav Neurosci 105: 817-825.

Sahuque LL, Kullberg EF, McGeehan AJ, Kinder JR, Hicks MP, Blanton MG et al. (2006). Anxiogenic and aversive effects of corticotropin-releasing factor (CRF) in the bed nucleus of the stria terminalis in the rat: role of CRF receptor subtypes. Psychopharmacology 186: 122-132.

Sakanaka M, Shibasaki T, Lederis K (1986). Distribution and efferent projections of corticotropin-releasing factor-like immunoreactivity in the rat amygdaloid complex. Brain Res 382: 213-238.

Schulz DW, Mansbach RS, Sprouse J, Braselton JP, Collins J, Corman M et al. (1996). CP-154,526: A potent and selective nonpeptide antagonist of corticotropin releasing factor receptors. Proc Natl Acad Sci USA 93: 10477-10482.

Sullivan GM, Apergis J, Bush DE, Johnson LR, Hou M, Ledoux JE (2004). Lesions in the bed nucleus of the stria terminalis disrupt corticosterone and freezing responses elicited by a contextual but not by a specific cue-conditioned fear stimulus. Neuroscience 128: 7-14.

Sun N, Cassell MD (1993). Intrinsic GABAergic neurons in the rat central extended amygdala. J Comp Neurol 330: 381-404.

Swerdlow NR, Britton KT, Koob GF (1989). Potentiation of acoustic startle by corticotropin-releasing factor (CRF) and by fear are both reversed by alpha-helical CRF (9-41). Neuropsychopharmacology 2: 285-292.

Toufexis D, Davis C, Hammond A, Davis M (2005). Sex differences in hormonal modulation of anxiety measured with lightenhanced startle: possible role for arginine vasopressin in the male. J Neurosci 25: 9010-9016.

Van Pett K, Viau V, Bittencourt JC, Chan RK, Li HY, Arias C et al. (2000). Distribution of mRNAs encoding CRF receptors in brain and pituitary of rat and mouse. J Comp Neurol 428: 191-212.

Waddell J, Morris RW, Bouton ME (2006). Effects of bed nucleus of the stria terminalis lesions on conditioned anxiety: aversive conditioning with long-duration conditional stimuli and reinstatement of extinguished fear. Behav Neurosci 120: 324-336.

Walker DL, Davis M (1997a). Anxiogenic effects of high illumination levels assessed with the acoustic startle paradigm. Biol Psychiatry 42: 461-471.

Walker DL, Davis M (1997b). Double dissociation between the involvement of the bed nucleus of the stria terminalis and the central nucleus of the amygdala in light-enhanced $v s$ fearpotentiated startle. J Neurosci 17: 9375-9383.

Walker DL, Davis M (2002a). Light-enhanced startle: further pharmacological and behavioral characterization. Psychopharmacology 159: 304-310.

Walker DL, Davis M (2002b). Quantifying fear potentiated startle using absolute $v s$ percent increase scoring methods: implications for the neurocircuitry of fear and anxiety. Psychopharmacology 164: 318-328.

Walker DL, Davis M (2008). Role of the extended amygdala in short-duration versus sustained fear: a tribute to Dr. Lennart Heimer. Brain Struct Funct 213: 29-42.

Walker DL, Toufexis DJ, Davis M (2003). Role of the bed nucleus of the stria terminalis versus the amygdala in fear, stress, and anxiety. Eur J Pharmacol 463: 199-216.

Wynn PC, Hauger RL, Holmes MC, Millan MA, Catt KJ, Aguilera G (1984). Brain and pituitary receptors for corticotropin releasing factor: localization and differential regulation after adrenalectomy. Peptides 5: 1077-1084. 